\title{
The effect of study preparation on test anxiety and performance: a quasi-experimental study
}

This article was published in the following Dove Press journal:

Advances in Medical Education and Practice

\author{
Hasan Yusefzadeh (D) \\ Jamileh Amirzadeh Iranagh $\mathbb{D D}^{2}$ \\ Bahram Nabilou (D) ${ }^{3}$ \\ 'Department of Health Management and \\ Economics, School of Public Health, \\ Urmia University of Medical Science, \\ Urmia, West Azerbaijan, Iran; \\ ${ }^{2}$ Department of Public Health, School of \\ Public Health, Urmia University of \\ Medical Sciences, Urmia, Iran; ${ }^{3}$ Social \\ determinants of health Research Center, \\ Department of Health Management and \\ Economics, School of Public Health, \\ Urmia University of Medical Sciences, \\ Urmia, Iran
}

Background: Health care education is an important issue in the development of countries, and student's academic achievement plays an important role in this respect. Test anxiety can affect the academic performance of students. This study aimed to investigate the effect of study preparation on test anxiety and performance of public health students.

Methods: This quasi-experimental study investigated the effect of study preparation on reducing test anxiety and improving the performance of public health students at Urmia University of Medical Sciences, Urmia, Iran, in the academic year 2016-2017.

All second- and third-year bachelor's students in public health major were assigned into the intervention $(n=20)$ and control groups $(n=25)$. The assignment was based on the study preparation items and the defined benchmark.

Data on general stress and test anxiety were collected by subjective self-assessment via paper-and-pencil surveys in the first week of the semester and before the final exam, respectively.

Results: No significant difference was found in the level of general stress between the two groups at the beginning of the semester $(p=0.55)$ based on the study preparation items. The level of test anxiety in the intervention group (47.90) was lower than in the control group (34.64) at the end of the semester $(p=0.001)$. The mean value of exam scores was higher in the intervention group ( $p=0.015$ ).

Conclusions: The intervention reduced the level of test anxiety and improved the performance of students. Faculty members and heads of the departments should help students learn about the study preparation over the semester with engagement in learning-oriented approaches and class activities.

Keywords: performance, education, anxiety, study preparation, Iran

Increasing attention is being paid to the quality of teaching and learning in health care education worldwide. There is also pressure to improve the skills and abilities of graduates to face future job challenges. ${ }^{1,2}$

Students' academic achievement plays an important role in providing countries with competent graduates for national development. ${ }^{3}$ Many studies have been conducted to identify and analyze the various factors affecting the academic performance of students. Some of these factors include students' effort, learning preferences, entry qualifications, class attendance, ${ }^{4}$ anxiety, ${ }^{5}$ lack of motivation, and lack of supervision on education ${ }^{6}$ and habits of study. ${ }^{7}$

Probably the most comprehensive part of research that has examined the students' experiences under different testing conditions can be derived from the field of anxiety literature, which describes various circumstances which negatively
Correspondence: Bahram Nabilou Health Management and Economics, School of Public Health, Urmia University of Medical Sciences, Nazloo Paradise. Sero Road, Urmia, West Azerbaijan 5756 II6III, Iran

Tel +98443275 2300;

Tel +989143491219

Fax +984432770047

Email nabahram@yahoo.com; bnabil@umsu.ac.ir 
or positively affect the performance of students. ${ }^{8}$ Indeed, test anxiety is one of the effective factors causing the students to perform poorly. ${ }^{9}$ In this regard, health care students perceive a higher level of stress, anxiety, and depression than students of other fields ${ }^{10}$ or students at higher academic levels ${ }^{11}$ and female students. ${ }^{12}$

Some stressor factors, among health care students, were excessive course load, study habits and skills, parents' expectations, little physical activity, and extracurricular activities. ${ }^{13-15}$

The method of presenting health care education has changed from a passive lecture-based method to an active self-learning manner. ${ }^{1,2,16}$ Changing study habits, active learning, problem-solving training, and encouraging students to study with a work schedule can reduce test anxiety. ${ }^{17,18}$

Students who suffer from test anxiety frequently experience distraction in exams and problems in preparing for exams. ${ }^{19}$ Several consequences of test anxiety include long period of the study, increased dropout rates at the university, exam failures, as well as physical and psychological impairments. ${ }^{20}$ A number of factors affect test anxiety. Students' perception about their knowledge and inability to enhance their learning has been included as the factors affecting student's achievement and their level of stress. ${ }^{21}$

Test anxiety reflects itself in students' complaints of lacking enough time to prepare for the exams or study the course materials, or being dissatisfied with the academic performance in previous assessments. ${ }^{22}$ Some research on test anxiety has focused on gender differences, which has frequently reported that female students experience higher levels of test anxiety than their male counterparts. ${ }^{23,24}$

Research on study habits in Iran suggests that study preparation during the semester is a challenge, and most students prefer to study on the free periods just before the exams and on the eve of the exams. ${ }^{25-28}$ The effect of anxiety on academic achievement makes it a necessity to recognize problems and develop a plan to control them. Accordingly, this study was designed to investigate the effect of the schedule-based study preparation on reducing test anxiety and improving performance of students.

\section{Materials and methods}

\section{Design}

This quasi-experimental study was conducted in the academic year 2016-2017, at Urmia University of Medical Sciences, Iran.

\section{Participants}

Two classes of second- and third-year bachelor's students in public health major were selected as subjects of the study ( $\mathrm{n}=45)$.

For the purpose of facilitating allocation process, the study preparation items and content are defined as: refresher course in the beginning of class sessions, class presentations, end-session summaries, suggestions, questions, and answers. Scoring of activities was also defined. Finally, classroom activities and related scorings were explained to all of the students (Table 1).

Participating in the first three activities altogether (named triple pack) was defined as the benchmark of assignment into the intervention group. A single selection of triple-pack components was not allowed. Participation of students was voluntary in the remaining activities defined in study preparation.

Students were consulted about participating in the defined items and announced their level of participation. Regarding the consultation and defined benchmark, candidates fulfilling the benchmark were assigned as intervention group $(\mathrm{n}=20)$. On the other hand, the control group $(n=25)$ included other students. Subjects were unaware of the defined benchmark and to which group they had been assigned.

Class presentation topics and details were proposed by students and finalized by the lecturer. Topics and dates of class presentations were also determined based on students' preferences and syllabus order.

Students had identical and constant conditions for a quasi-experimental study including the lecturer, field of study, the lesson and syllabus, location of the class, the final exam questions, and even the level of general stress in two groups. These were the criteria for selecting second- and third-year students of public health as intervention and control groups.

The students were told that they could earn $10-35 \%$ of the total scores from class activities; accordingly, the scores of the final exam for intervention and control groups were defined as 13 and 18 out of 20 .

Lesson sessions were conducted in 1:30 hr sessions weekly during the semester. At the beginning of the class sessions, one or two students from the intervention group performed a refresher course for reviewing and updating the contents of the previous session. End-session summaries were also held by students at the end of the class session. Questions were asked and answered by students 
Table I Minimum and maximum scores of study preparation items

\begin{tabular}{|l|l|l|l|l|l|}
\hline NO & Type of activity & Score & Maximum score & Selection of activity by students & $\begin{array}{l}\text { Selection of students by } \\
\text { lecturer }\end{array}$ \\
\hline \multirow{4}{*}{} & Question & $0.25-0.5$ & 2 & $\mathrm{~V}$ & - \\
& Answer & $0.25-0.5$ & 2 & $\mathrm{~V}$ & - \\
& End-session summary & $05-0.75$ & 1.5 & MFI & $\mathrm{R}$ \\
& Refresher course & $0.5-\mathrm{I}$ & 2 & MFI & $\mathrm{R}$ \\
& Class presentation & $\mathrm{I}-2$ & 3 & MFI & - \\
\hline
\end{tabular}

Abbreviations: $\mathrm{V}$, voluntary; MFI, mandatory for intervention group; R, random; BS, based on the order of syllabus.

during class sessions, and, if necessary, the lecturer would give them a supplementary explanation. Candidates of class presentations reviewed and finalized their work with lecturer before presentation. Class presentations were convened from the second week of the semester to the last week. Students' suggestions about the lesson and classroom activities were considered during the semester.

The participant students in both groups received their grade feedback at the end of each session. The final exam of the selected lesson was held for both groups at one place at the same time.

\section{Instruments}

Two instruments were applied for assessing the level of general stress and level of test anxiety in study groups.

\section{Stress symptom inventory (SSI)}

SSI has 50 items which measure four domains of cognitive (7 items), emotional (9 items), behavioral (11 items), and physical (23 items) symptoms. A 6-point Likert scale (do not exist $=0$, very low $=1$, low $=2$, moderate $=3$, high $=4$, and very high=5) was used to answer the items of SSI. Then, the scores of each domain were calculated by combining related items. The validity and reliability of SSI had already been determined by Khodayari Fard in Iran. The internal consistency of SSI was reported as follows: total alpha coefficient 0.82 , cognitive domain 0.80 , emotional domain 0.83 , behavioral domain 0.83 , and physical domain $0.81{ }^{29}$

\section{Test anxiety inventory (TAl)}

TAI had 25 questions and the subjects answered based on a 4-point Likert scale (never $=0$, rarely $=1$, sometimes $=2$, and often $=3$ ). The minimum and maximum points in this questionnaire were 0 and 75, respectively. A higher score indicated more anxiety. The validity and reliability of TAI had been determined in $\operatorname{Iran}^{30}$ and used in several studies. $^{31-33}$ Abolghasemi et al reported reliability
Cronbach's alpha for all, male, and female subjects as $0.94,0.92$, and 0.95 , respectively.

\section{Data collection}

\section{Phase I}

The researchers administered SSI to the students of the intervention and control groups in the first month of the semester. Both groups completed SSI simultaneously and at one place to assess the level of general stress and possible differences. Basically, there was no need to determine the level of test anxiety at the beginning of the semester. Therefore, SSI was performed to determine and compare the overall stress level between the two groups. Stressors in a college have different types: physical, financial, academic, and psychological. ${ }^{34}$ It was important to ensure that the level of general stress was similar in both groups at the start of the semester.

\section{Phase II}

Data collection for test anxiety was performed using TAI just before the final exam of the selected lesson. Both groups completed TAI simultaneously at one place to determine and compare the level of test anxiety.

\section{Data analyses}

Data analyses were conducted using SPSS software (IBM, SPSS Inc., Chicago, IL, USA), and the results were described in frequency tables. The Shapiro-Wilk test was applied to test data normality. Also, independent $t$-test was used to compare exam scores, the general stress, and test anxiety between the two study groups. Correlation between general stress, test anxiety, and exam scores was investigated via Pearson correlation coefficient. The significance level of tests was set at $p<0 \cdot 05$. 


\section{Ethical considerations}

Voluntary and anonymous completion of the questionnaires was declared in the first session of the lesson, and the students provided written informed consent to participate in the study. The project was approved by Educational Development Center of vice deputy of education as well as the ethics committee of vice deputy of research and technology in UUMS (IR.UMSU.REC.1395.506).

\section{Results}

The eligible subjects included 45 students, with 20 of them assigned in the intervention group. The mean ages of the students in the intervention group and the control group were $22.3 \pm 1.83$ and $23.48 \pm 1.22$, respectively. The differences in means of age were statistically significant between the two groups $(p=0.014)$. Ninety-eight percent of the students were female $(n=44)$ and the same number of them were also natives of one province $(n=44)$. Scores of study preparation activities were calculated for all students based on the scale defined in Table 1. Scores of study preparation activities in the intervention group ranged between 5 and 7 (25-35\% of total score) from the total score of 20 . The mean scores of general stress, its domains, test anxiety, and total test scores for the selected lesson are listed in Table 2.

Normality of data based on Shapiro-Wilk test showed that general stress data, test anxiety data $(p=0.768)$, and exam scores $(p=0.163)$ had a normal distribution. Therefore, parametric tests were used in data analysis.

Independent $t$-test revealed no significant difference in means of general stress scores between the intervention group $(72.60 \pm 0.11 .84)$ and the control group (72.36 $\pm 0.35 .18)(p=0.98)$.

The results of the independent $t$-test revealed that there was a statistically significant difference in the means (mean difference $=13.26$ ) of test anxiety scores between the intervention group and the control group $(p=0.001)$. The mean of test anxiety in the control group was higher than that in the experimental group. The difference in the means of test scores (mean difference $=1.6$ ) was also significant ( $p=0.014$ ) between the two groups, which was higher in the intervention group (Table 2). Pearson correlation coefficient revealed no significant correlation between the means of test anxiety scores, general stress, and exam scores.

\section{Discussion}

The results of this study suggested that the level of general stress did not differ significantly between the two groups at the start of the semester. On the other hand, based on the results, the level of test anxiety in the intervention group was lower than that in the control group at the end of the semester. Performance of students in the intervention group was higher than in the control group. Participation and active attendance in class could lead to low levels of anxiety and better performance (Figure 1).

The level of general stress in the present study was found to be low and acceptable, which was similar to that in other studies in Iran. ${ }^{35,36}$ In other words, students in the two groups did not differ in terms of general stress, and their stress was found to remain at the same level as other

Table 2 Mean, SD, maximum and minimum scores of level of test anxiety, general stress, its domains, and test scores in studied groups $(n=45)$

\begin{tabular}{|c|c|c|c|c|c|c|c|c|c|c|c|c|c|c|}
\hline \multirow[b]{2}{*}{ Variable/value } & \multicolumn{4}{|c|}{ Control group } & \multicolumn{4}{|c|}{ Intervention Group } & \multicolumn{4}{|c|}{ Overall/Total } & \multirow{2}{*}{$\begin{array}{l}\text { SSI/ } \\
\text { TAI } \\
\text { SSI }\end{array}$} & \multirow{2}{*}{$\begin{array}{l}\text { Date } \\
\text { SOS }\end{array}$} \\
\hline & Mean & SD & Min. & Max. & Mean & SD & Min. & Max. & Mean & SD & Min. & Max. & & \\
\hline Test anxiety & 47.90 & 11.84 & 23 & 71 & 34.64 & 12.85 & 9 & 58 & 40.53 & 13.96 & 9 & 71 & SSI & sos \\
\hline General stress & 72.60 & 28.85 & 24 & 128 & 72.36 & 35.18 & 21 & 139 & 72.47 & 32.16 & 21 & 139 & SSI & sos \\
\hline $\begin{array}{l}\text { Physical stress } \\
\text { domain }\end{array}$ & 28.30 & $13.8 \mid$ & 12 & 55 & 28.44 & $|4.7|$ & 3. & 59 & 28.38 & 14.15 & 3. & 59 & SSI & sos \\
\hline $\begin{array}{l}\text { Behavioral stress } \\
\text { domain }\end{array}$ & 16.85 & 7.43 & 5 & 30 & 17.68 & 9.30 & 4 & 36 & 17.31 & 8.44 & 4 & 36 & SSI & sos \\
\hline $\begin{array}{l}\text { Emotional stress } \\
\text { domain }\end{array}$ & 15.40 & 6.06 & 4 & 27 & 14.24 & 8.001 & 3 & 35 & 14.76 & 7.15 & 3 & 35 & SSI & sos \\
\hline $\begin{array}{l}\text { Cognitive stress } \\
\text { domain }\end{array}$ & 12.05 & 5.59 & 3 & 24 & 12.00 & 6.82 & 1 & 26 & 12.02 & 6.23 & I & 26 & SSI & sos \\
\hline General stress & 72.60 & 28.85 & 24 & 128 & 72.36 & 35.18 & 21 & 139 & 72.47 & 32.16 & 21 & 139 & TAI & EOS \\
\hline Exam scores & 14.52 & 2.012 & 11.5 & 19 & 16.14 & 2.26 & 9 & 19 & 15.42 & 2.25 & 9 & 19 & - & EOS \\
\hline
\end{tabular}

Abbreviations: SSI, stress symptom inventory; TAI, test anxiety inventory; SOS, start of semester; EOS, end of semester. 


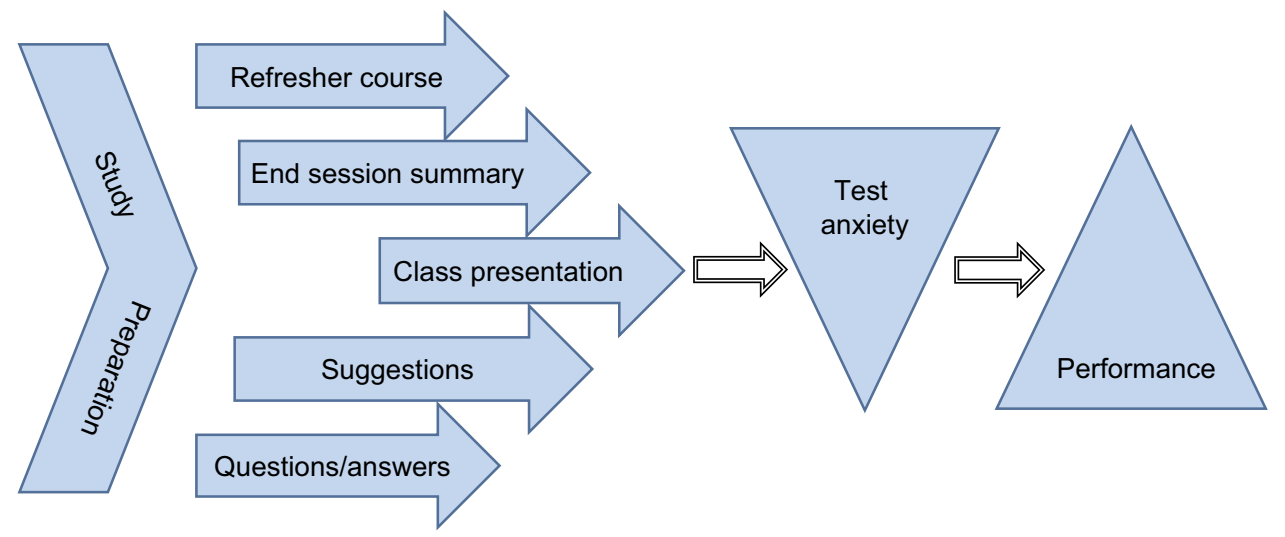

Figure I Study preparation activities affecting the level of test anxiety and students' performance.

people in the community. This meant that the conditions for the intervention were available in relation to factors related to general stress in two groups. The precision of experimental studies depends on many factors. ${ }^{37}$

The results of a study at Birjand University of Medical Sciences showed a significant, negative correlation between the domains of metacognitive learning strategies including planning, monitoring and control, regulation, as well as regulatory activity and test anxiety. ${ }^{38}$ The present study applied schedule-based participatory learning which had the above elements with relatively similar results.

Some studies confirmed that cognitive skills had an inverse association with test anxiety. The results of this study were consistent with the studies of Mohammadi et $\mathrm{al}^{38,39}$ and Mohammadi et al. ${ }^{39}$

Previous studies reported that goal orientation approach was negatively associated with test anxiety. The students who were goal oriented during their studies and had learning planning would become less anxious. ${ }^{33,40,41}$

Students with high levels of test anxiety obtained lower scores than their low anxious peers. ${ }^{42,43}$ The present study showed that the students in the intervention group had less anxiety and obtained higher scores in comparison with students in the control group.

Kwan suggested daily quiz as a powerful remedy for reducing test anxiety among students. ${ }^{18}$ The results of Alkadri study confirmed that from the student's point of view, formative assessment may provide a deeper understanding of learning. ${ }^{44}$ In the present study, the students in the intervention group were regularly evaluated every session. Frequent evaluation of students can lead them to study further, gain better results, and be less concerned about the final exam.
Hora emphasized an instructional plan that reinforces self-regulatory behavior of students as a solution to reduce test anxiety. ${ }^{45}$ In this study, the intervention group had a defined work plan which was issued at the beginning of the semester. According to some studies, highly evaluative environments resulted in more test anxiety for students. ${ }^{46}$ Assigning work plan and frequent assessment seem to be helpful for students who do not have a study program.

Haseli and Rezaii ${ }^{47}$ reported the positive effect of critical thinking treatment sessions on mitigating test anxiety. ${ }^{47}$ Active learning strategies could include critical thinking to encourage students to improve their performance.

Based on the results of Duraku's study, learners at bachelor's level mentioned lack of preparation, weaknesses in time management, and deficiency in reading skills as factors associated with test anxiety. ${ }^{48}$ As the results of this study showed, the above-mentioned issues were generally eliminated by active learning and regular evaluation.

In a study conducted by Suarez et al, ${ }^{49}$ the difference in test anxiety level was not significant across entry levels. ${ }^{49}$ The present study included two consecutive courses in public health in bachelor's degree. One year of seniority in starting the course probably did not affect test anxiety and general anxiety.

Studies also suggested a low level of test anxiety in participatory learning compared to lecture-based method. ${ }^{50-52}$ This confirms the results of this study which encouraged students for active learning and scheduled class activities.

Özbiçakçi et $\mathrm{al}^{53}$ advised nursing trainers to incorporate participative approaches in learning activities to reduce anxiety. Meanwhile, the role of lecturers is important in applying participatory and active methods. ${ }^{53}$ 
Some studies reported an association between general anxiety and test anxiety in students. ${ }^{54}$ In the present study, there was not any significant association between general anxiety and test anxiety and its domains where the level of general stress was assessed to be the same for other people. Different results can be attributed to the differences in the sample of two studies, coupled with societies with different socioeconomic characteristics, different age groups, and different educational levels.

This quasi-experimental study had high precision, and all the effective factors were taken into account as much as possible. Anonymous completion of questionnaires was a limitation, and as a result, a case by case study of general stress and test anxiety was not possible. A small number of students can also be considered as a constraint.

Further, pre-post comparison about test anxiety seems to be impossible. Indeed, the test anxiety is an emotion of future achievement, and the level test anxiety may be 0 at the start of the semester.

\section{Conclusion}

Test anxiety before and during exams has a significant impact on the performance of students. The intervention influenced test anxiety and exam scores significantly. The results showed if students think a significant proportion of their exam score was already accounted for by class activity, they will experience less stress during exam days. There is a need for anxiety-reduction programs in health sciences colleges. Test anxiety can be managed through applying study preparation and active methods by lecturers. Faculty members and heads of departments should let students learn about study preparation during the semester and support their engagement in class activities and accomplishment of courses.

\section{Disclosure}

The authors report no conflicts of interest in this work.

\section{References}

1. Devlin M, Samarawickrema G. The criteria of effective teaching in a changing higher education context. High Educ Res Dev. 2010;29 (2):111-124. doi:10.1080/07294360903244398

2. Rathnakar U, Ullal SD, Pai PG, Rajeshwari S, SUDhaKaR P, Shivaprakash G. Is small group teaching among the under graduate dental students really effective? J Clin Diagn Res. 2011;5(4):822-825.

3. Norhidayah A, Kamaruzaman J, Syukriah A, Najah M, Azni Syafena Andin S. The factors influencing students' performance at Universiti Teknologi MARA Kedah, Malaysia. Manage Sci Eng. 2009;3(4):81.
4. Mlambo V. An analysis of some factors affecting student academic performance in an introductory biochemistry course at the university of the West Indies. Caribbean Teach Scholar. 2011;1:2.

5. Neemati N, Hooshangi R, Shurideh A. An investigation into the learners' attitudes towards factors affecting their exam performance: a case from Razi university. Procedia Soc Behav Sci. 2014;98:1331-1339. doi:10.1016/j.sbspro.2014.03.550

6. Siabani S, Moradi MR, Siabani H, et al. Students' view points on the educational problems in medical school of Kermanshah university of medcial sciences (2007). J Kermanshah Univ Med Sci. 2009;13:2.

7. Ali S, Haider Z, Munir F, Khan H, Ahmed A. Factors contributing to the students academic performance: a case study of Islamia university sub-campus. Am J Educ Res. 2013;1(8):283-289. doi:10.12691/education-1-8-3

8. Cassady JC, Gridley BE. The effects of online formative and summative assessment on test anxiety and performance. J Technol Learn Assess. 2005;4(1):n1.

9. Rana RA, Mahmood N. The Relationship between Test Anxiety and Academic Achievement. Bull Educ Res. 2010;32(2):63-74.

10. Heinen I, Bullinger M, Kocalevent R-D. Perceived stress in first year medical students-associations with personal resources and emotional distress. BMC Med Educ. 2017;17(1):4. doi:10.1186/s12909-017-0929-9

11. Dawood E, Al Ghadeer H, Mitsu R, Almutary N, Alenezi B. Relationship between test anxiety and academic achievement among undergraduate nursing students. $J$ Educ Pract. 2016;7 (2):57-65.

12. Rupani MP, Parikh KD, Trivedi AV, et al. Cross-sectional study on exam anxiety among medical students of a tertiary care teaching hospital of western India. Natl J Community Med. 2016;7(5):449-454.

13. Chauhan H, Shah H, Chauhan S, Chaudhary S. Stress in medical students: a cross sectional study. Int J Biomed Adv Res. 2014;5 (6):292-294.

14. Simran G, Sangeeta N, Lily W. Evaluation of Examination Anxiety Status and Its Associated Factors among First Professional Medical (MBBS) Students. IJIMS. 2015;2(8):1-11.

15. Solanky P, Desai B, Kavishwar A, Kantharia S. Study of Psychological Stress among Undergraduate Medical Students of Government Medical College. Surat. Int $J$ Med Sci Public Health. 2012;1:38-42.

16. Saleh AM, Al-Tawil NG, Al-Hadithi TS. Teaching methods in Hawler college of medicine in Iraq: a qualitative assessment from teachers' perspectives. BMC Med Educ. 2012;12(1):59. doi:10.1186/ 1472-6920-12-59

17. Kazemi H, Vaziri M, Abedi A. The effectiveness of problem solving training on test anxiety and social anxiety in primary school students. Soc Cogn. 2016;5(1):98-110.

18. Kwan F. Formative assessment: the one-minute paper vs. the daily quiz. J Instructional Pedagogies. 2011;5:1.

19. Fehm L, Fydrich T. Prüfungsangst: Fortschritte der Psychotherapie. Göttingen: Hogrefe. Google Scholar; 2011.

20. Köster S, Rupp-Freidinger C, Dieker-Müting J. Angst vor der Prüfung. Wie Dozenten Prüfungsängste von Studierenden auffangen und mildern können [Afraid of the exam. How lecturers can absorb and mitigate student exams]. In: Berendt B, Voss HP, Wildt Hrsg J, editors. Neues Handbuch Hochschullehre (Loseblatt- Sammlung) [New Handbook University Lecture (Loose Leaf Collection)]. Berlin: Raabe, 2005; 1-36. German.

21. Carveth JA, Gesse T, Moss N. Survival strategies for nurse-midwifery students. J Nurse Midwifery. 1996;41(1):50-54.

22. Abouserie R. Sources and levels of stress in relation to locus of control and self esteem in university students. Educl Psychol. 1994;14(3):323-330. doi:10.1080/0144341940140306

23. Núñez-Peña MI, Suárez-Pellicioni M, Bono R. Gender differences in test anxiety and their impact on higher education students' academic achievement. Procedia Soc Behav Sci. 2016;228:154-160. doi:10.1016/j.sbspro.2016.07.023 
24. Bandalos DL, Yates K, Thorndike-Christ T. Effects of math self-concept, perceived self-efficacy, and attributions for failure and success on test anxiety. J Educ Psychol. 1995;87(4):611-623. doi:10.1037/0022-0663.87.4.611

25. Alamdar H, Bakhtar M, Sheikh Fathollahi M, Rezaeian M. A survey on the study habits in students of Rafsanjan university of medical sciences in 2015. J Rafsanjan Univ Med Sci. 2017;16(2):155-168.

26. Koushan M, Heidari A. Evaluation study of habits in students of medical school sciences Sabzevar. J Sabzevar Sch Med Sci Health Serv. 2007;13(4):185-189.

27. Mohammadi M, Dadkhah B, Mozaffari N, Nemati A. To understand the effective studying between Ardabil city university students in 2006 year. Koomesh. 2008;9(2):93-98.

28. Torshizi M, Varasteh S, Poor Rezaei Z, Fasihi R. Study habits in students of Birjand university of medical sciences. Iranian $\mathrm{J} \mathrm{Med}$ Educ. 2013;12(11):866-876.

29. Khodayari Fard M, Parand A. Stress and Ways to Cope with It. Tehran: Tehran University Publication; 2007.

30. Abolghasemi A, Asadi M, Najarian B, Shokrkn H. Construction and validation of test anxiety scale for students in third grade during the academic guidance of Ahvaz. J Educ Psychol. 1996;3:61-74.

31. Ahmadpanah M, Keshavarz M, Haghighi M, et al. Higher emotional intelligence is related to lower test anxiety among students. Neuropsychiatr Dis Treat. 2016;12:133.

32. Tehrani LA, Majd MA, Ghamari M. Comparison of self-efficacy, test anxiety and competitiveness between students of top private schools and public schools. Mediterr J Soc Sci. 2014;5(23):2749.

33. Monfared M, Nejad ARO. The effect of teaching life skills on test anxiety, problem-solving ability and curriculum achievement motivation nine-grade studentsin Shiraz. IJHCS. 2016;1:1.

34. Calloway SJ, Kelly P, Ward-Smith P. Stressors and barriers to help seeking for psychological distress among students attending a rura university. J Rural Ment Health. 2012;36(1):3-10. doi:10.1037/h0094774

35. Farhadi V, Doostzadeh M, Chehri A. The effect of early family-centered intervention on stress syndrome in the mothers of children with autism. J Kermanshah Univ Med Sci. 2015;19(5):254-260.

36. Doostzadeh M, Hemmati Alamdarloo G, Shojae S. The Effectiveness of Family-Centered Early Intervention on Stress Symptoms of Mothers of Childern with Hearing Impairment. JCMH. 2016;3(1):81-93.

37. Cook TD, Shadish WR, Wong VC. Three conditions under which experiments and observational studies produce comparable causal estimates: new findings from within-study comparisons. $J$ Policy Anal Manage. 2008;27(4):724-750. doi:10.1002/pam.v27:4

38. Mohammadi Y, Kazemi S, Tahan H, Lalozaee S. Relationship between metacognitive learning strategies, goal orientation, and test anxiety among students at Birjand university of medical sciences. JMed Educ. 2017;16:1.

39. Mohammadi Y, Kaykha A, Sadeghi A, Kazemi S, Raeisoon M. Relationship of metacognition learning strategy and locus of control with academic achievement of students. EducStrategy Med Sci. $2015 ; 8(5): 323-328$.
40. Bembenutty H, McKeachie WJ, Karabenick SA, Lin Y-G. The Relationship between Test Anxiety and Self-Regulation on Students " Motivation and Learning. Washington, DC. 1998.

41. Garrido Vargas M Relationship of Self-Regulated Learning and Academic Achievement among English Language Learners [PhD thesis]. The University of Arizona. 2012.

42. Syed M, Memon A, Ashraf A, Sheikh A, Al Suwaidi A, Shiekh RB Presence of test anxiety and association with forms of assessment among health sciences students in Ajman, UAE. President's Message.66.

43. Jamali H, Ghalenoei M, Yazdani Aval M, et al. Prevalence of anxiety among environmental and occupational health students in Qazvin university of medical sciences Iran, in 2015. JOHE. 2017;6 (3):128-135. doi:10.29252/johe.6.3.128

44. Al Kadri HM, Al-Moamary MS, van der Vleuten C. Students` and teachers' perceptions of clinical assessment program: A qualitative study in a PBL curriculum. BMC Res Notes. 2009;2(1):263. doi:10.1186/1756-0500-2-263

45. Hora MT, Oleson AK. Examining study habits in undergraduate STEM courses from a situative perspective. Int J STEM Educ. 2017;4(1):1. doi:10.1186/s40594-017-0055-6

46. Hancock DR. Effects of test anxiety and evaluative threat on students' achievement and motivation. J Educ Res. 2001;94(5):284-290. doi:10.1080/00220670109598764

47. Haseli Z, Rezaii F. The effect of teaching critical thinking on educational achievement and test anxiety among junior high school students in Saveh. Eur Online J Nat Soc Sci. 2013;2(2s):168.

48. Duraku Z. Factors influencing test anxiety among university students. Eur J Soc Behav Sci Future Acad. 2016;1(1):2325-2334. doi:10.15405/ejsbs.206

49. Suarez MJ, Quimbo MAT, Anxiety T. Selected personal factors as determinants of academic performance of undergraduate online learners. Malaysian $J$ Distance Educ. 2016;18(1):29-51. doi: $10.21315 /$ mjde2016.18.1.3

50. Karimi Moonaghi H, Mohammady A, SalehMoghaddam A, Gholami H, Karshki H. Comparing the effects of cooperative learning to lecture trainings on the motivational beliefs and self-regulating learning strategies. Iranian J Med Educ. 2014;14(5):393-402.

51. Keramati MR, Hedari RA, Enayati Novinfar A, Hedayati A. The Impact of Cooperative Learning on Students' Science Academic Achievement, and Test Anxiety. Journal of Educational Ennovations. 2012;11(44);83-98.

52. Sharifi M, Aflakifard H. Effectiveness of problem solving skills training on test anxiety in high school students in Meymand. $J$ Res Psychol Educ. 2016;2(7):1-16.

53. Özbiçakçi S, Bektas M, Cetin E, Uysal N. Comparison of basic computer training strategies and their effects on the level of computer anxiety in Turkish nursing students. Comput Inform Nurs. 2011;29(4):239-244.

54. Sridevi K. A study of relationship among general anxiety, test anxiety and academic achievement of higher secondary students. J Educ Pract. 2013;4(1):122-130.
Advances in Medical Education and Practice

\section{Publish your work in this journal}

Advances in Medical Education and Practice is an international, peerreviewed, open access journal that aims to present and publish research on Medical Education covering medical, dental, nursing and allied health care professional education. The journal covers undergraduate education, postgraduate training and continuing medical education including emerging trends and innovative models linking education, research, and health care services. The manuscript management system is completely online and includes a very quick and fair peer-review system. Visit http://www.dovepress.com/testimonials.php to read real quotes from published authors. 